\title{
Electronic Textile Reparability
}

Dorothy Hardy ${ }^{\mathrm{a}{ }^{*}}$, Rachael Wickenden ${ }^{\mathrm{a}}$, Angharad McLaren ${ }^{\mathrm{a}}$

aSchool of Art and Design, Nottingham Trent University, Bonington Building, Dryden Street, Nottingham, NG1 4GG, UK.

*Corresponding author: Dorothy Hardy:

${ }^{1}$ Since completing this work, Dorothy Hardy has become a freelance research communicator.

Email: dorothy@dorothyhardyassociates.co.uk

Phone: +44 7800710266

\section{Rachael Wickenden:}

Email: rachael.wickenden2015@my.ntu.ac.uk

\section{Angharad McLaren:}

Email: angharad.mclaren@ntu.ac.uk

Phone: +44 1158482709

\section{Highlights}

- Mixing electronics with textiles can shorten product lifetimes

- Integrated or hidden electronics can hinder repair and recycling

- Modular designs facilitate washing and repair

- Good labelling indicates location and care of electronics

- E-textile design should take repair and disposal into account

\begin{abstract}
The market for electronic textiles is predicted to expand rapidly, with great benefits expected from some products, at the same time as creating a large and challenging waste stream. The amalgamation of electronics with textiles can lead to shortened product lifetimes, as breakage of either the electronics or textile components can lead to product failure. Reparability is therefore crucial, extending electronic textile lifetimes and decreasing the overall volume of waste produced.

Three commercially available electronic textile garments were examined. The assessment revealed varying degrees of reparability, from batteries that could not be replaced to fully rechargeable and removable components. Standard clothing care processes, such as washing and ironing, could limit maintenance and cause irreversible damage to electronic components.

Running counter to the design and engineering objective of full integration between textile and electronics, a modular approach to electronic textiles, where electronics are held in pockets rather than integrated into textile structures, should be reconsidered to prolong product lifetime by enabling maintenance and repair. Labelling could inform users about appropriate care of the electronics within electronic textiles, but presence of electronics was not always mentioned. The findings of this study provide rich descriptive data about the reparability of products in a rapidly growing market.
\end{abstract}




\title{
Keywords
}

Electronic textiles; repair; recycling; waste; clothing; electronics.

\author{
Abbreviations \\ CE: Conformité Européenne (European Conformity) \\ EEE: Electrical and Electronics Waste \\ E-textiles: Electronic Textiles \\ HR: Heart Rate \\ ICT: Information and Communication Technology \\ QR: Quick Response code \\ WEEE: Waste Electrical and Electronic Equipment Recycling \\ WRAP: Waste and Resources Action Programme
}

\section{INTRODUCTION}

Textiles with integrated electronics, known as electronic or E-textiles are predicted to see considerable commercial growth (Hayward, 2019), which is currently led by industry (Sharma, 2018), with ongoing research taking place in academia (Rein et al., 2018; Satharasinghe et al., 2018; Zysset et al., 2013).

There have been a number of studies that investigate a broad range of concerns that this product category presents in terms of sustainability, should they be adopted by the mass market (Köhler, 2013a; Ossevoort, 2013; Sametinger et al., 2019), particularly that their incompatibility with existing recycling and disposal schemes would lead to significant loss of valuable resources and risks to human health and the environment (Köhler, 2008; Köhler et al., 2011). These studies consider Etextiles as a novel and emerging category rather than considering more familiar hybrid electronictextile products that are readily available, such as heart-rate monitoring garments, electric blankets and novelty items such as light-up, musical Christmas jumpers. Whilst these products may appear crude in comparison with the future vision of E-textiles as part of the ubiquitous computing paradigm, the repair challenges they pose can inform the design of more sustainable future developments.

Product longevity has been recognized as a key strategy in minimizing the environmental impact of the electronics (Defra, 2019) and clothing industry (Cooper et al., 2016). Longevity describes a product's active life-span, taking into account user behaviour and sociocultural influences, as well as design and manufacture (Cooper, 2010)(p4). Maximising reparability is one method of improving product longevity, but the combination of both electronics and textiles mean the skillset required to repair E-textiles is much broader than that required for either traditional textile or electronic products. The way electronics and textiles fail, and therefore the reason for which they require repair, are also distinct and the means to address or prevent product failure can be opposing. For example, the use of textile products necessitates a distinct set of everyday care processes, such as washing and ironing to remove stains and creases, but these can damage even specifically designed electronic components (Eichhoff et al., 2013).

The integration of electronics with textiles could also accelerate the rate at which everyday products are replaced due to disparity between expected lifetimes of each. In the UK, for example, a jacket is expected on average to be actively used for over 5 years (Langley et al., 2013) whereas the lifecycle of a smartphone is usually less than 2 years (Baldé et al., 2017)(p. 21). These contradictory issues are 
explored in this study, by seeking insights from a review of current E-textile products and assessing how these can impact on the incorporation of longevity through design.

\subsection{AIMS AND SCOPE}

This study investigated the reparability of currently available E-textile garments, analysing the particular challenges they present in consideration of consumer expectations, behaviour and product use. It aimed to establish ways in which potential obstacles to product longevity could be overcome through design practices and processes. The research questions were:

- How easily can E-textile garments be used, maintained and repaired?

- Which aspects of E-textile products encourage or support consumers to prolong product lifetime?

- What are the barriers and enablers to designing E-textile products for longevity?

The evaluation led to best practice recommendations on designing E-textiles to maximise reparability and separability. The findings were based on three E-textile products, which though not representative of the entire range of commercially available products, provide rich descriptive data about the reparability of products in a rapidly growing market about which relatively little is known.

\section{METHOD: ANALYSIS OF E-TEXTILES}

The study adopted an exploratory approach, reviewing three readily available commercial E-textile garments (Wickenden et al., 2019). These were selected from a range of price points and distinctive types of functionality of available commercial E-textile garments.

Each product was assessed to find:

1. Design and manufacture: What was the product made from? How were electronics integrated into the garment?

2. Labelling: Did any labelling refer to electronics being present within the product? Did the labelling include instructions for disposal, such as the crossed wheelie bin symbol? Was there a CE mark to show that the product conformed with European health, safety and environmental standards (United Kingdom, 2012)?

3. Product use: what was the intended purpose of the E-textile product? What were the implications for use in relation to maintenance and repair?

4. Electronic reparability: Could batteries or other electronic components be repaired or replaced relatively easily?

5. Textile repair: Could the textile components of the products be cared for, maintained, and repaired? How straightforward would this be?

6. Manufacturers' instructions on repair, reuse and recycling: Were these provided with the product or via links to the internet? What support was available?

The findings were evaluated against eco design and longevity guidelines for electronics and clothing (Cooper et al., 2016; ECMA, 2010; Köhler, 2013), with the purpose of identifying barriers and opportunities for design to support the creation of longer lasting E-textile garments. The following section gives the background, clarifying the necessity for this study.

\section{CONTEXT}

The electronics and textiles sectors, both associated with high volume, low cost, and largely short-life products are priority areas for the UK Waste Resources Action Program (WRAP, 2018). It is estimated that the market for E-textiles will be worth over \$1.4bn by 2030 (Hayward, 2019). E-textile 
waste will add to global waste streams that for 2017 consisted of 48 million tonnes of waste clothing (Ellen MacArthur Foundation, 2017) and 50 million tonnes of electronic waste (Forti et al., 2020), with electronics estimated to be the world's fastest growing waste stream (ibid). The amount of this waste that was specifically due to E-textiles is unknown, but personal communications with UK textile recyclers in 2018 showed that they received E-textiles, including electric blankets and clothing with novelty features such as lights and/or sound, and that these were sent to landfill, unless clean, functioning and marketable, in which case they were exported for resale.

Concern about the negative environmental and social footprint of clothing and textiles led to the launch in 2008 of the UK Sustainable Clothing Action Plan (SCAP) 2020 (Defra, 2010). This was followed in 2014 by UK Electrical and Electronic Equipment Sustainability Action Plan 2025 (ESAP) (WRAP, 2017a). In theory, both plans could apply to disposal of E-textiles, but issues are caused by the hybrid nature of these products, that are likely to contain both commonly used textile materials, such as cotton, polyester, and acrylic, plus electrical and electronic components, such as batteries and wires (Köhler, 2013b).

The Waste Electrical and Electronic Equipment (WEEE) Directive 2012/19/EU (European Parliament Council of the European Union, 2012) and Restriction of Hazardous Substances Directive (RoHS) 2011/65/EU (The European Parliament and the Council of the European Union, 2011) were set up to ensure that harmful materials were not used in electrical and electronic equipment, and that this waste stream was managed and kept separate from general waste. However, there is insufficient legislation and infrastructure to support current WEEE requirements, compounded by lack of knowledge of correct disposal requirements (Cole et al., 2016). Importantly, directives pertaining to WEEE only apply to clothing or other E-textile products when they include 'a fundamental feature which needs electricity to function, such as a gym top with heart rate monitor, heated walking jacket or a hat with integral speakers'(Environment Agency, 2018). While E-textiles that 'can still work properly as clothing without the electrical functions' such as clothing with 'novelty lights and/or sound' or where the electronics can be removed for the product to be cleaned are exempt (ibid). This somewhat ambiguous distinction leaves room for manufacturers to avoid WEEE legislation and means that many E-textiles will be sent directly to landfill, not to a WEEE waste stream. On a positive note some progress has been made by setting out standardisation needs for E-textiles and a recommendation to design for durability (British Standards Institution, 2015). More generally, a regulatory framework is being put in place aimed at design for product durability and repair (Maitre-Ekern and Dalhammar, 2016), but E-textiles pose unique challenges to current waste processing systems. They are likely to exacerbate sustainability issues and complicate end-of-life treatment before manufacturing technology, legislation and infrastructure are sufficiently able to handle current electronic waste, $82.6 \%$ of which was not 'documented: collected/properly recycled' globally in 2019 or the world's clothing waste, $73 \%$ of which was estimated to ultimately end up in landfill (Ellen MacArthur Foundation, 2017).

\subsection{E-TEXTILES AND ELECTRONICS REPAIR}

The development of E-textiles has been occurring for over a century, with an increasingly high level of integration between textiles and electronics, from attachment of electronics onto the surface of textiles, or within pockets (Buechley, 2006; Hughes-Riley et al., 2018) to inclusion of conductive materials such as metals within textile structures . Electronics have been integrated using weaving (Hardy et al., 2019b; Orth, 2009; Veja, 2014); embroidery (Erdem et al., 2016); knitting (Chen et al., 2019; Mbise et al., 2015), plus the containment of electronics within textile yarn structures (Dias, 2016; Hardy et al., 2019a) and fibre structures (Zeng et al., 2014).

Basic electronics repair includes use of standard battery types which are easy to locate and replace (Köhler, 2013b), but the repair of more complex electronics is often hindered by lack of design for repair (Chamberlain, 2012; Rosner and Ames, 2014). Close integration of electronics with textiles is seen as key to the development of sophisticated E-textiles (Cherenack and Van Pieterson, 2012) but 
this may limit reparability and reduce product longevity, with difficulties in locating sources of electrical continuity failure, and in replacing parts embedded within textile structures.

\subsection{Clothing \& REPAIR}

A large amount of clothing is discarded due to minor damage such as small holes, seams or hems unravelling, or buttons falling off, with lack of skills, knowledge, equipment or time to undertake minor repairs reported as barriers to mending by consumers (McLaren and McLauchlan, 2015). Further causes of product failure in clothing include staining and loss of shape from washing (WRAP, 2017b). These apply to E-textile garments, with the additional risk of damage to the electronics, that must be designed to either withstand the processes of clothing care and maintenance, such as laundering, drying and ironing (Hardy et al., 2020), or must always be removed beforehand. Care labels that include instructions for the electronics could inform consumers in order to help prevent damage, but research has shown that these labels are rarely followed after the first wash and often poorly understood, ignored or removed (Mclaren et al., 2016).

Clothing repair can be enabled through provision of consumer support, services, mending kits and spare parts, such as buttons or thread to fix a hole, and developing modular clothing for simple replacement of worn or damaged parts (Cooper et al., 2016). Many consumers consider professional clothing repair services prohibitively expensive and not easily accessible (Gwilt, 2014).

\subsection{ENABLING E-TEXTILES REPAIR}

Built in obsolescence in clothing and electronics has benefitted industry (Zallio and Berry, 2017) but legislation is now being created to counteract this. Shortening the life of products has been made illegal in France (Maitre-Ekern and Dalhammar, 2016). Other countries could follow suit (Bonifacic, 2020; Cole et al., 2016), which could force manufacturers to design E-textiles that are physically durable, reparable and separable. Ideally, the value to the consumer is great enough to warrant repair, rather than treating an E-textile as a short-lifespan, disposable electronic or textile. There is a surge of interest within some consumer segments (such as cost-conscious younger consumers) for more information and knowledge about clothing repairs (Charter and Keiller, 2016). This is consistent with the emergence of Repair Cafés and resurgence in craft skills (Buechley et al., 2014).

A product's active life is also determined by its emotional durability: the emotional and experiential connection between person and object, ensuring that products are cared for and likely to be repaired if damaged. Clothing is often replaced because it appears out of fashion or looks worn (Langley et al., 2013) rather than being 'broken'. Similarly, an exploratory study found that only $31 \%$ of smartphones were replaced because they were broken (Martinho et al., 2017). E-textiles could be discarded due to component failure or due to lack of emotional durability. This could be counteracted by careful choice of materials and modules plus longer life guarantees, backed up with appropriate testing and consumer support.

\section{RESULTS AND DISCUSSION}

Examples of best practice in E-textile design for reparability are discussed in this examination of three E-textile products.

\subsection{The PREMIUM: LEVI'S® COMMUTER ${ }^{\text {TM }}$ TRUCKER JACKET WITH JACQUARD ${ }^{\text {TM }}$}

The 2017 version of the Levi's ${ }^{\circledR}$ Commuter ${ }^{\mathrm{TM}}$ Trucker jacket with Jacquard ${ }^{\mathrm{TM}}$ by Google (Figure 1(a)) was purchased in August 2018 for US \$350. A Bluetooth enabled electronic tag (Figure 1(b)), attached to the jacket enabled operation of the wearer's phone by swiping and tapping the jacket cuff which incorporated Jacquard ${ }^{\mathrm{TM}}$ threads woven into the fabric to create a sensor (Figure 1(c)). These threads included metal, silk and polyurethane (Poupyrev et al., 2016). 


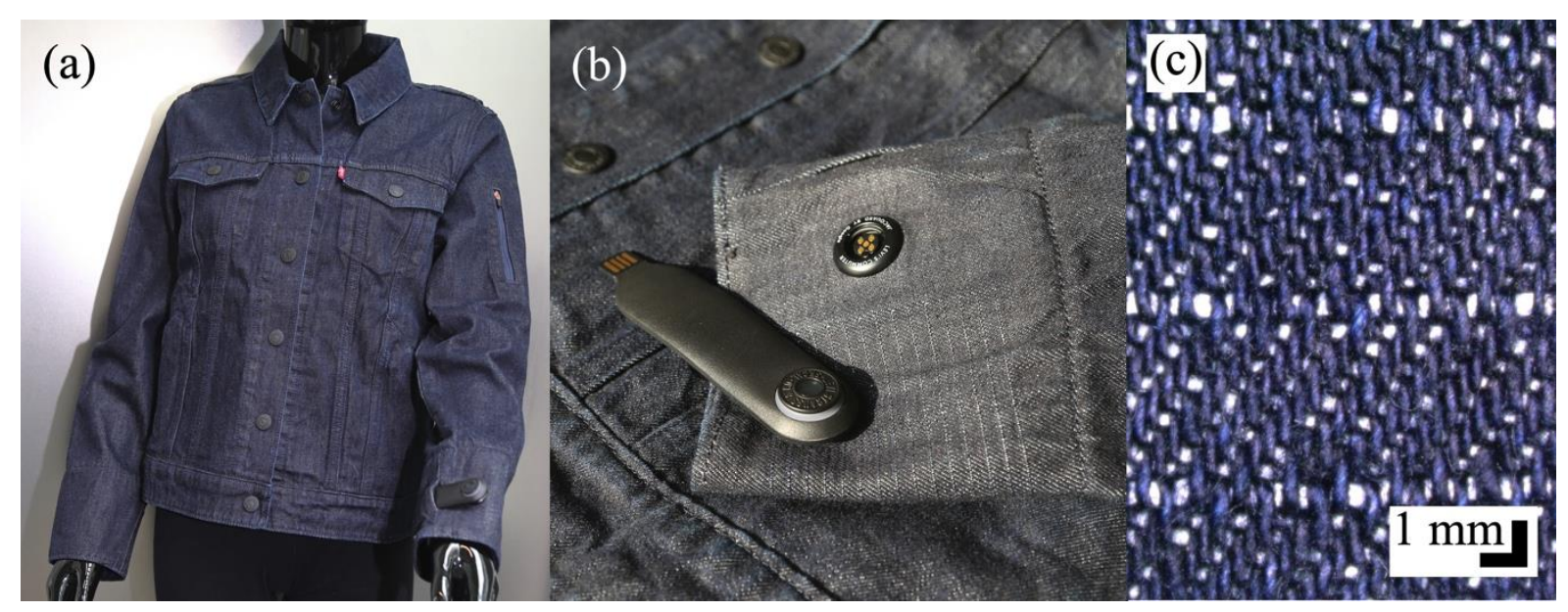

Figure 1(a): Levi's ${ }^{\circledR}$ Commuter ${ }^{\mathrm{TM}}$ Trucker jacket with Jacquard ${ }^{\mathrm{TM}}$ by Google with USB tag attached to the left cuff; (b) The USB tag placed on top of the left cuff; (c) Detail of the Jacquard ${ }^{\mathrm{TM}}$ threads within the left cuff.

The denim jacket was labelled with a standard garment label (Figure 2(a)) noting composition (outer $100 \%$ cotton, lining $86 \%$ polyester and $14 \%$ elastane, trim $93 \%$ polyamide and $7 \%$ elastane) and laundry care instructions (Figure 2(b)); indicating that it should be washed at $30^{\circ} \mathrm{C}$, not dry cleaned, and that the left cuff containing the Jacquard ${ }^{\mathrm{TM}}$ threads should not be ironed. Information stating that the jacket had been tested by the developers to last 'at least 10 washes' was in the leaflet that accompanied the jacket and on the product website (Google, 2019), but not on the laundry care label. Considering that this jacket was promoted as a cycling 'commuter' jacket, it is likely that it would require frequent washing to keep fresh. Only being able to withstand 10 washes and no dry cleaning would limit the active life-span of this E-textile product dramatically compared to the expected 5 years of a standard denim jacket (Langley et al., 2013), known for being durable and long lasting due to denim's innate ability to age gracefully.

The jacket's labelling included the WEEE crossed wheelie bin symbol (Figure 2(a)), indicating that the product was considered to be electrical and electronics waste (EEE) and should not be disposed of in household waste, and the CE (European Conformity) mark ${ }^{1}$. Products are classed as EEE when their primary function is considered to be electrical or electronic, so not all E-textiles fall under this classification.

A snap fastener on the cuff allowed attachment of the electronic tag that could be connected to the user's mobile phone via the purpose designed Jacquard ${ }^{\mathrm{TM}}$ app. This enabled a smartphone to recognise four user gestures on the Jacquard ${ }^{\mathrm{TM}}$ cuff (up-swipe, down-swipe, double tap and hold). The Jacquard $^{\mathrm{TM}}$ threads were woven into the fabric of the cuff, and as such were completely inseparable from the other textile fibres. If the cuff were damaged due to everyday wear and tear, which is particularly common on cuffs, or by accidentally ironing the area despite the care label advising against it, then advanced darning skills and knowledge of the construction and connectivity of the conductive threads would be required in order to repair it.

Perhaps acknowledging these challenges, the design was simplified in the 2019 version of the jacket, which does not contain the Jacquard ${ }^{\mathrm{TM}}$ threads (Bohn, 2019). Photos of the later design on the project Jacquard $^{\mathrm{TM}}$ web page give some indication of the electronic connections and the few small electronic components that would be found within the sleeve (Google, 2020). However, user repair of the jacket electronics, including the battery, would render the warranty invalid (Google, 2017a). This was partly for safety reasons, but the lack of clear explanation of the way in which the jacket's electronics functioned, and no encouragement for those wishing to repair their jackets, made repair of this

\footnotetext{
${ }^{1}$ The CE mark indicates that a product conforms to the health, safety and environmental protection standards of the European Economic Area.
} 
product unlikely. There was no take-back scheme specifically for this jacket after the one-year warranty had expired, although the company does have a scheme to take back denim (Levi's ${ }^{\circledR}, 2019$ ).

The electronic tag could be recharged by USB connection, but the battery was sealed within its plastic casing and could not be replaced. Google offered a support service for battery issues, but it was unclear if this applied after the warranty expired (Google, 2017b). This information was not printed on the garment care label. Instead, it was in the pamphlet that accompanied the jacket and on the product's website, reachable via a QR code label on the inside of the jacket (Figure 2(a)).

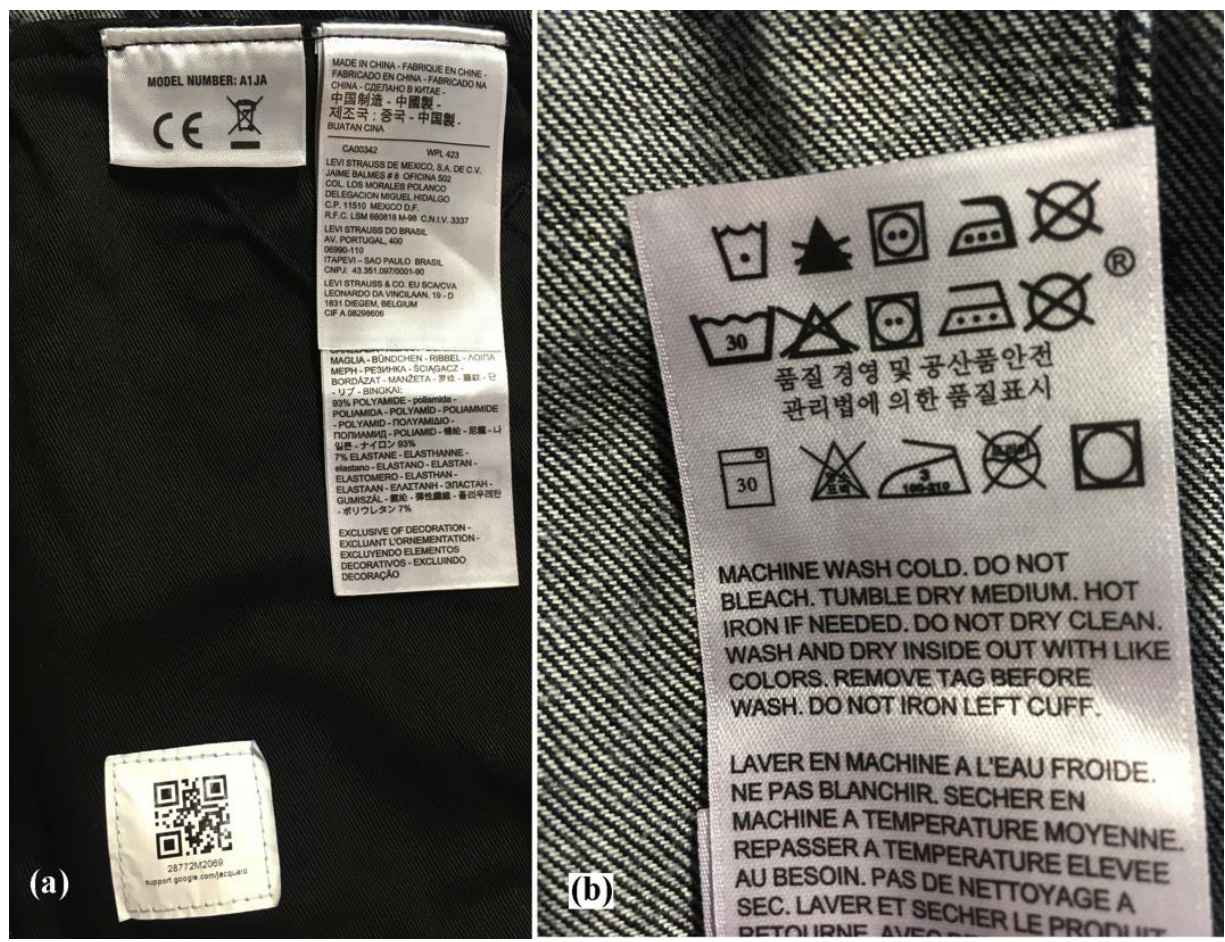

Figure 2: Labelling inside the jacket (a) Labels showing the CE mark and crossed wheelie bin symbol, fabric composition, and a QR code; (b) Reverse of the fabric composition label showing washing instructions.

In summary, repair of the electronics by the jacket's users was actively discouraged. This, combined with limited washability, would limit its active life as an E-textile garment. The jacket provided a novel method of accessing some features on a smartphone, without touching the phone itself. This was a limited level of extra functionality when evaluated against the additional complexity and cost of the jacket (HAL 90210, 2017), which raises questions about the need for the E-textile functionality when considering the environmental impact of the materials and components.

\subsection{THE FUNCTIONAL: A HEART RATE MONITORING SPORTS BRA}

A Heart Rate (HR) monitoring sports bra branded 'Berlei' (Figure 3) was purchased from Amazon in August 2017 for $£ 23.14$. The bra was designed to hold an electronic module at the front of using the snap fasteners shown in Figure 3(a). The module would transmit readings from the electrode (Figure 3(b)) on the inside of the bra, detecting the electrical activity of the heart, to a device such as a sports watch.

HR monitor modules and watches are made by a number of brands, including Garmin and Polar (Garmin UK, 2019; Polar UK, 2020). These were not supplied with the bra, which came with no information to indicate the compatibility of the product with different modules or display devices. Without the electronic module it was unclear if the bra and module would reliably detect and transmit a HR signal. Issues with the accuracy of signals from HR monitoring devices within clothing (Dias and Silva Cunha, 2018) make it likely that this E-textile was suitable for monitoring trends in heart 
rate rather than for precise measurement. A separately bought electronic module would, however, be less likely to be disposed of with the bra at the end of the product life, minimizing associated electronic waste with this E-textile.

The product was labelled as containing $47 \%$ polyamide, $37 \%$ polyester and $16 \%$ elastane (exclusive of trims). The label indicated that the garment was hand wash only and could not be ironed or tumble dried (Figure 3(c)). The hand washing criterion is not desirable in a garment that, worn next to the skin during exercise, would require frequent washing. There were no WEEE or CE symbols on the labelling, and the garment did not have a warranty. The nylon and polyester in the bra were likely to be long lasting fibres (Grishanov, 2011; Gupta, 2013), but the bra contained 16\% elastane which over time could cause unsightly and un-rectifiable 'grin-through' whereby elastane fibers poke through the textile (Kadolph and Marcketti, 2016). In addition, if damage were to occur to the textile, its warp knit construction could not be easily replicated by hand so the wearer would have to accept a visible repair.

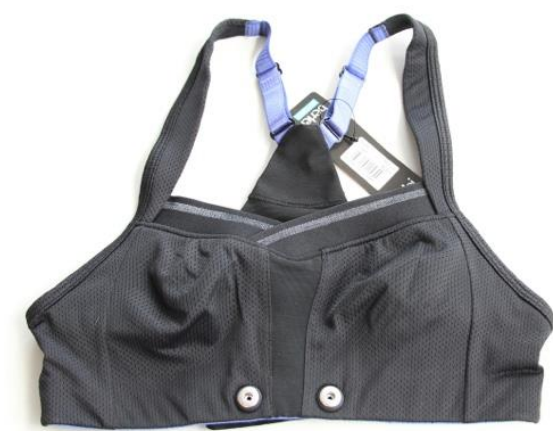

(a)

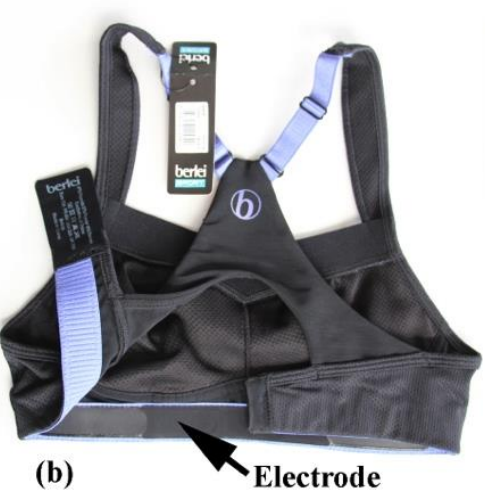

(b)

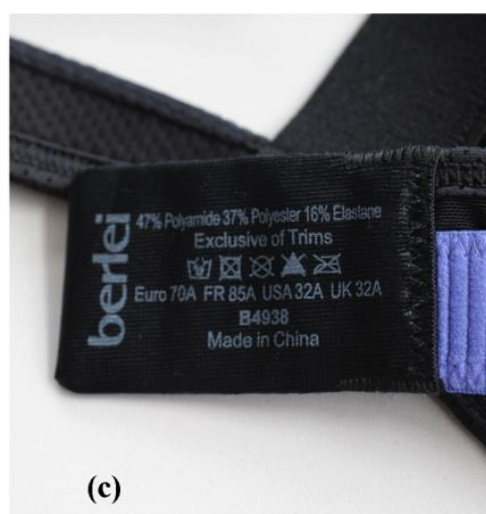

(c)

Figure 3. The heart-rate monitoring sports bra: (a) Exterior front with press stud connections on the centre lower front for attachment of a module to transmit signals from the sensor to another device; (b) The reverse of the bra with the electrode indicated on the interior; (c) The label showing the hand washing instruction.

The bra's electrode was investigated by peeling it away from the underband after applying heat (Figure 4). The electrode was made up of layers of polymer-based film bonded to each other and to the fabric. Some of the layers of film contained carbon particles making them conductive, with other non-conductive film areas acting as an insulator (Wickenden et al., 2019). The main 'electronic' item in the product was the conductive tape assembly. Repair of this, to recreate a functioning electrode would have been beyond the technical capability of most consumers. The cost of carrying out the repair by a specialist, if one could be found, would be likely to be greater than the cost of a new sports bra, making repair an unlikely choice.

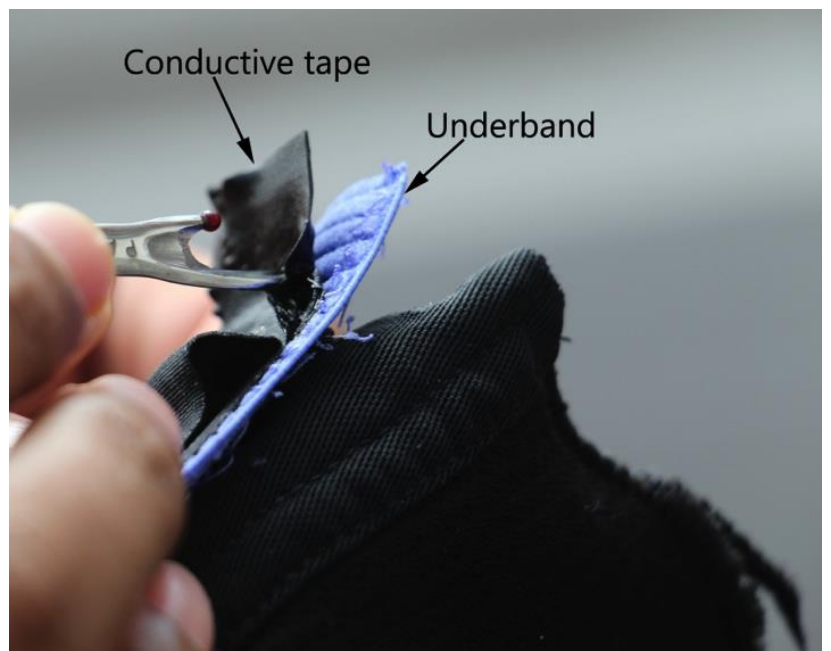

Figure 4: Part of the dissembled bra with the conductive tape peeled away from the blue underband after application of heat. 
The bra was purchased through a third party, not directly from Berlei. Contact with the Berlei customer service team confirmed that the product was genuine but discontinued several years previously (Personal communication, 27/06/2019). Hence, the consumer would be unlikely to have support in the case of product incompatibility or failure.

In summary, this was a cheap product, unlikely to be valued by the user enough to warrant repair. The conductive tape and bra materials were likely to fail if machine washed rather than hand washed. The bra could have been used simply as a sports bra, if the functionality was unreliable. Discarding the product was likely to cause issues with separation of materials in current textile recycling systems.

\subsection{THE NOVELTY: ILLUMINATED CHRISTMAS JUMPER}

A Next brand women's Christmas jumper (Figure 5(a)) was purchased second-hand in July 2018 for $£ 6$. The date or price of its first purchase was unknown, but prices for this type of product in December 2018 were around $£ 30$. The reindeer's nose would light up and play a Christmas jingle when pressed, because of an electronics pod in a pocket on the reverse of the jumper front (Figure 5(b)). The knitted jumper contained a label indicating that the textile content was $100 \%$ acrylic and washable in a standard $40{ }^{\circ} \mathrm{C}$ wool wash cycle (Figure 5(c)). Washing the garment inside out was recommended, maybe to protect the outside of the garment from undue wear in the wash, but the care label made no reference to the electronics, either in terms of materials or any instruction indicating whether the pod should be removed for washing. Unsurprisingly for a relatively low-cost novelty item purchased second hand, the jumper did not come with a warranty.

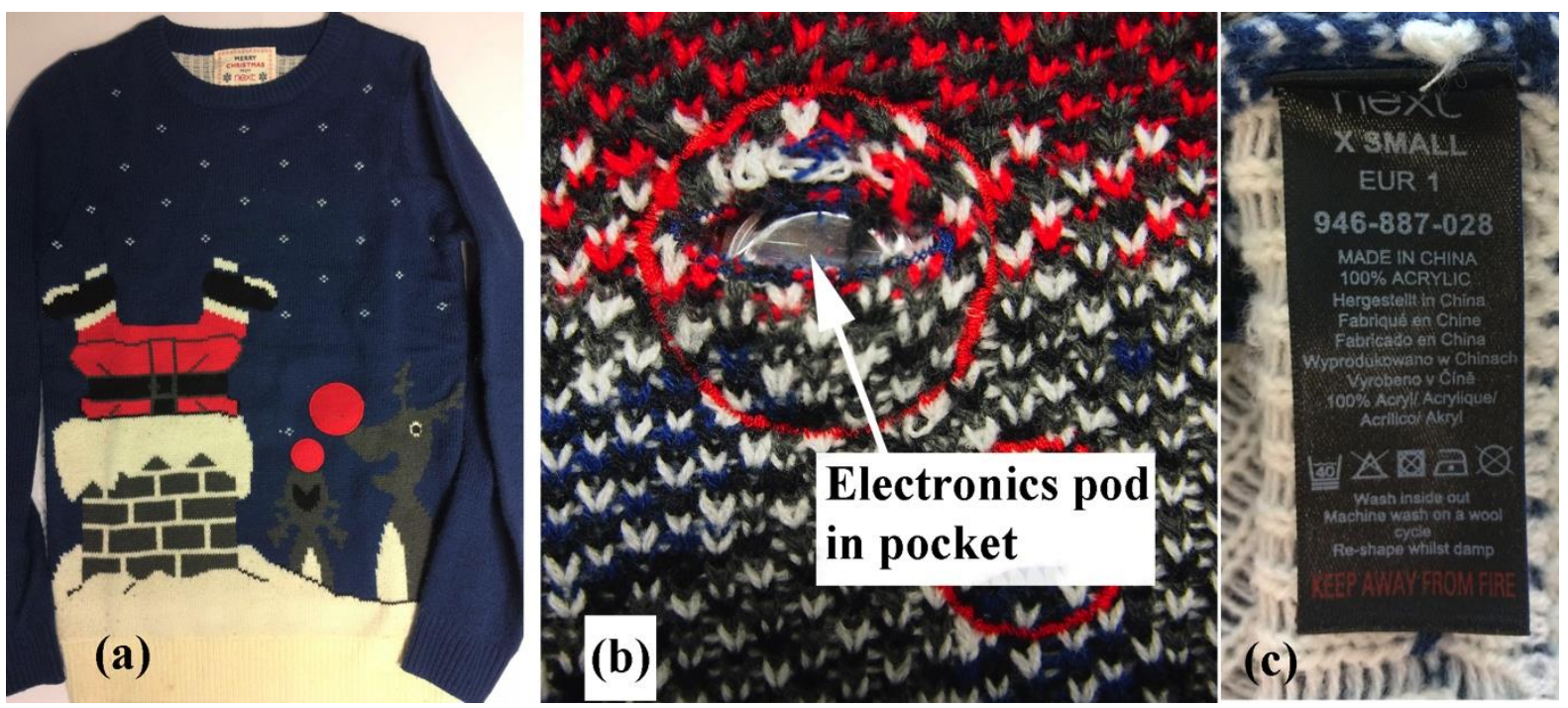

Figure 5(a): Christmas jumper with larger reindeer's nose that illuminates when pressed; (b) A detail of the inside of the jumper showing a pocket containing an electronics pod that illuminated the jumper and played tunes when pressed; (c) The jumper label with washing instructions but no mention of the electronics.

Acrylic is wool-like in appearance, but cheaper and less prone to shrinkage (Kumar et al., 2016). However, acrylic has worse pilling behavior, causes static and is less comfortable due to lower thermal retention and absorbency. Its oleophilic qualities also mean it holds oil-based stains and odors (Kadolph and Marcketti, 2016). The used Christmas jumper showed pilling all over, plus several stains; as a low-cost fibre with only moderate appearance retention, clothing made from acrylic is unlikely to be repaired. Christmas jumpers are a seasonal product not for year-round wear; a factor already adding to plastics pollution (Smithers, 2019).

The electronics were encapsulated in a sealed plastic pod $4 \mathrm{~cm}$ in diameter (Figure 6(a)) and held tightly in a pocket on the reverse of the garment. The care label did not carry the WEEE symbol despite the pod, manufactured by 'Bliss Electronic' (2020), containing many electronic components. 
The pod was disassembled to reveal the contents Figure 6(b). The batteries could be slid from their holders, to enable replacement, but this was not possible without breaking the sealed plastic pod.

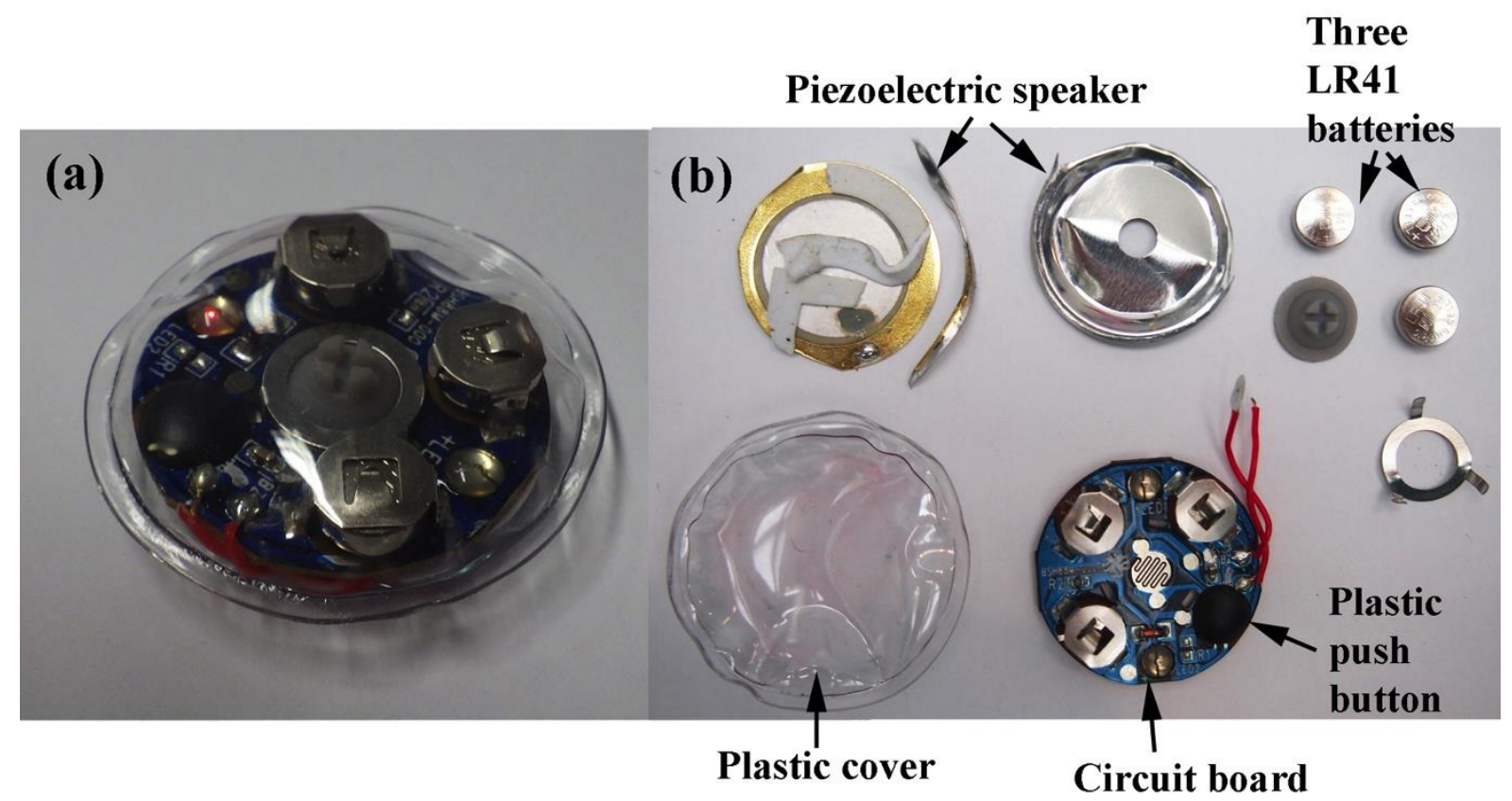

Figure 6: Electronics pod: (a) As removed from the jumper; (b) Separated into components.

In summary, although the garment demonstrated good practice by having the electronics in a removable pod, there was no guidance that this should be removed for washing. The jumper was likely to require frequent washing due to the tendency of acrylic to retain stains and odour. The sealed pod would have deterred users from battery replacement or repair of the electronics. Cutting the pod open left it more vulnerable to subsequent damage, for example due to liquid spillage. This E-textile garment was unlikely to be repaired due to its low cost and propensity to age poorly.

\section{RECOMMENDATIONS TO SUPPORT REPARABILITY}

The examination of the three products demonstrated key areas to consider when designing reparable E-textiles. These are summarised here as recommendations, together with wider requirements for standardisation and assessment of the need for E-textiles.

\subsection{DESIGN AND MANUFACTURE}

E-textile design requires consideration of materials, style and appropriate use of technology to create functional products. One challenge is to ensure that the electronics can withstand the repeated flexing and wetting that is expected of many textile products through wear and care. Both of these processes are likely to cause breakages. One broken connection can prevent the electronics from functioning, making repair necessary to ensure electrical continuity. Ideally electronic components that cannot be washed are removable. Modular design is one method of enabling this.

\subsubsection{Modularity}

The Christmas jumper exhibited modularity, as the electronics were contained in a removable pod that could easily be separated for washing, repair, and recycling. Both the bra and jacket contained separate electronic modules, giving a level of modularity to enable electronics to be separated, but both garments also contained electrical components that were inseparable from the fabric. This created a heterogeneous material that would be very difficult to repair, recycle or separate and reuse 
(Köhler, 2013a) and would be at greater risk of damage from care processes such as washing and ironing.

E-textile designers could draw on examples of modularity such as detachable collars and detailing (Townsend et al., 2020); and modular clothing that can be updated each season (Deploy, 2020) to prolong a product's active life. In the field of medical E-textiles, stroke survivors preferred the partial modularity of an E-textile sleeve that could be worn with any outfit, as opposed to one incorporated into a specific piece of clothing (Yang et al., 2018).

The batteries, connectors and electronic parts used in E-textiles should ideally be robust, limiting the need for repair; and standard, so that they are relatively easy to replace. Rechargeable, replaceable batteries are a basic requirement to support this.

\subsubsection{Material choices}

E-textiles need to be designed to avoid lower product lifetimes caused by failure of electronics amalgamated with textiles; or damage to either electronics or textiles through inappropriate user behaviours. The sports bra was made from appropriate materials and style for its intended use. The Levi's ${ }^{\circledR}$ jacket was made from durable denim (WRAP, 2013), in a classic garment style known for its longevity, so may be used after the electronics cease to function. This would rely on the consumer continuing to wear it after failure, or alternatively donating or selling on the garment. This was not actively encouraged in the product communications, but as a premium product users might want to capitalize on its value.

The electronics were not likely to be as durable as the garments. The Levi's ${ }^{\circledR}$ jacket 10 wash limit and the sports bra's requirement for hand washing did not reflect the reality of likely garment use and therefore threatened the products longevity through failure of the conductive components.

\subsubsection{Emotional durability}

Involving end-users of E-textiles in the design process could ensure that E-textiles that are created where they are needed, rather than as gimmicks (O'Connor, 2017), which may increase people's willingness to repair them. The Apple iPhone is more commonly repaired than other smart phones. This may be accounted for by greater emotional durability of the product because of design factors and better maintenance of resale value compared with other brands (Wieser and Tröger, 2016).

The Clothing Durability Dozen (Cooper et al., 2019) offers a range of strategies to increase clothing longevity including physical and emotional durability, and also notes the roles of alternative business models, communication and promotion, product labelling and longer life guarantees. These strategies can be equally useful when considering the longevity of E-textile products. Ideally, the value to the consumer is great enough to warrant repair, rather than treating an E-textile as a short-lifespan, disposable electronic or textile. Methods of repair need to be easy to discover, through labelling, web references and points of contact for assistance with cost-effective repair.

\subsection{LABELLING}

Labelling can signpost consumers to the locations and function of electronics within E-textiles, as well as giving information about care and repair.

All three E-textile products that were examined, were labelled with standard textile care labels informing consumers of their textile composition and laundry care requirements. However, only the Levi's ${ }^{\circledR}$ jacket, representing the premium end of the market, made any reference to the electronic components on the care label, indicating that the area containing the conductive threads should not be ironed. Information regarding the limited number of washes the Levi's ${ }^{\circledR}$ jacket could withstand was not found on the jacket, but in the pamphlet that accompanied the jacket and on the website (Google, 2019), meaning the consumer may remain unaware of this limitation. The Levi's ${ }^{\circledR}$ jacket was the only 
product that gave disposal instructions through the use of the WEEE symbol. The QR code inside the jacket linked the user to online resources making information easier to find should the original accompanying product pamphlet be unavailable. Making this clearer and more accessible on all Etextile garments would decrease the chance of accidental damage through inappropriate care.

Currently, material composition of trimmings, non-textile parts and any fibre in small percentages are not legally required on the labels of textile products (Department for Business Innovation and Skills, 2016), hence the electronics can be excluded. Development of new regulations for hybrid E-textile products would not only ensure correct care, maintenance and disposal but could also make repair more accessible. However, given that care labels are often overlooked, this should be as clear as possible in original product swing tags and accompanying marketing materials, with links to other forms of support recommended.

\subsection{STANDARDS}

Standardisation increases the feasibility of repair through the availability and lower price of components. Compatibility achieved through the standardisation of components is a recommended eco-design principal to ward against obsolescence (Köhler, 2013b). Standards for E-textile design, assembly and labelling could assist in forcing producers to make reparability a priority.

The Levi's ${ }^{\circledR}$ jacket used a standard USB connection to recharge the tag, making it widely compatible. The jacket software was only compatible with certain brands and versions of phone. This was likely to act as a form of built in obsolescence, with a change in phone possibly leading to a non-functioning jacket. The bra was compatible with a range of electronic modules, which could be seen as positive, but the fact the manufacturer took no responsibility for product compatibility created a risk that the product would not function. Any lack or loss of functionality could lead to the product being quickly discarded as it had a relatively low price and no warranty.

\subsection{BUSINESS MODELS THAT SUPPORT REPAIR PRACTICES}

Businesses can support repair practice by providing:

- Warranties: These give purchasers an expectation that product repair is supported by manufacturers. The Levi's ${ }^{\circledR}$ jacket was the only product examined that had a warranty. Inexpensive E-textiles are likely to be cheaper to replace than to repair.

- Spare parts: Ready availability of spare parts, such as buttons that are often provided with garments, would assist consumers in repairing products. Manufacturers of E-textiles would need to open about the ways electronics were incorporated into garments to give consumers confidence in finding and repairing faults.

- Support for repair: This could be provided through labelling; online information from manufacturers; provision of workshops; and advice on where to find local repair centres. Unfortunately, encouraging consumers to repair items could conflict with warranty conditions. Ideally manufacturers would work with consumers to enable optimum, cost-effective methods of maintaining products.

This all requires clear communication about and promotion of repair practices: a change of mindset from electronics hidden within textiles to a model in which electronics are an added extra that can be located within a garment that is worth caring about.

\subsection{VALUE VS IMPACT}

The novelty of smart materials such as E-textiles can mean that any transformation that uses their functional capability is seen as a success independent of whether it creates value to society (Karana et al., 2015). It is known, for example, that fitness trackers are often inaccurate, but their use is now 
widespread and encouraged (Gonzalez, 2017). Arguably the utility of E-textile products should be assessed in the context of their environmental impact, and the societal need for E-textile products is an issue deserving of further research (Berglin, 2008, p. 98). Some products are medically useful, such as heated clothing that can improve quality of life for sufferers from Reynaud's syndrome (Scott, 1988), but none of the examples in this study were essential to meet needs that could not achieved through other means. E-textile developers must weigh up the necessity of E-textiles in relation to the negative environmental impact they can have to ensure that E-textiles are created only as required.

\section{CONCLUSION}

The products analysed in this research contained electronics both attached to and amalgamated with textiles. The purpose of these E-textiles was to access a phone by touching a jacket cuff; monitor heart rate; and light up a jumper whilst playing music. The textiles ranged from durable denim to acrylic yarn with poor wear properties. The addition of electronics was likely to shorten the product lifespans when compared with classic textile equivalents, due to the potential failure of the electronics. Care and repair of the E-textiles was simplest where electronic and textile elements could easily be separated, through use of removable electronics pods or replaceable, rechargeable, batteries. Conversely, electronics bonded or woven with textiles were likely to fail due to washing and ironing, as well as being difficult to repair.

Labelling to indicate the presence and location of electronics would assist consumers in caring for Etextiles, but only one of the three products examined referred to electronics on its label. Ideally, labelling would provide signposting to repair, reuse and disposal instructions, with manufacturers providing repair services, warranties and take-back schemes.

Standardisation and legislation could further regulate the E-textiles market to ensure that products are created where needed in ways that encourage care, repair, reuse, recycling and disposal. Increased producer and consumer involvement in development of electronic textiles: their necessity, as well as their longevity, is required to halt the increase of an E-textiles waste stream that causes recycling and disposal problems. This will require a collaborative approach across textiles, electronics and product design disciplines, taking user-centred design approaches to create beneficial E-textiles.

\section{ACKNOWLEDGEMENTS}

The authors would like to thank the staff and students in the School of Art and Design at Nottingham Trent University who assisted in sourcing, examining and testing E-textiles as part of this research, including members of the Advanced Textiles Research Group and Clothing Sustainability Research Group. Thanks in particular to Achala Satharasinghe who advised on materials in the sports bra. His hands are shown in Figure 4.

Thank you to Emily Cole for taking the photos in Figures 3 and 4.

This journal paper was developed from the PLATE 2019 conference paper 'Electronic Textiles and Product Lifetimes: Teardowns' (Wickenden et al., 2019)

\section{FUNDING}

This work was funded through the 2018 Nottingham Trent University Sustainable Futures, Seedcorn Fund.

Dorothy Hardy's role in this research was funded through EPSRC grant EP/MO15149/1: Novel manufacturing methods for functional electronic textiles. 


\section{REFERENCES}

Baldé, Forti, Gray, Kuehr, Stegmann, 2017. The Global E-waste Monitor 2017 - Executive Summary [WWW Document]. URL https://www.itu.int/en/ITU-D/Climate-Change/Documents/GEM 2017/Global-E-waste Monitor 2017 .pdf (accessed 5.13.20).

Berglin, L., 2008. Interactive Textile Structures Creating Multifunctional Textiles based on Smart Materials [WWW Document]. https://www.divaportal.org/smash/get/diva2:876879/FULLTEXT01.pdf (accessed 9.15.20).

Bliss Electronic, 2020. BSH88M [WWW Document]. My Co. URL http://www.bliss.com.tw/index.php?r=products/details-page\&section=Apparel modules\&details=BSH88M (accessed 5.13.20).

Bohn, D., 2019. Google's Project Jacquard is available on new Levi's jacket [WWW Document]. The Verge. URL https://www.theverge.com/2019/9/30/20888909/google-levi-project-jacquardavailable-trucker-sherpa-jackets-price-design (accessed 5.13.20).

Bonifacic, I., 2020. EU plans to introduce sweeping "right to repair" legislation for electronics [WWW Document]. Endgadget. URL https://www.engadget.com/2020-03-11-eu-right-to-repairphones-tablets-computers.html (accessed 5.13.20).

British Standards Institution, 2015. Textiles and textile products - Smart textiles - Definitions, categorisation, applications and standardization needs. URL https://shop.bsigroup.com/ProductDetail?pid=000000000030245031 (accessed 9.15.20).

Buechley, L., 2006. A Construction Kit for Electronic Textiles, in: 2006 10th IEEE International Symposium on Wearable Computers. IEEE, pp. 83-90. https://doi.org/10.1109/ISWC.2006.286348 (accessed 3.28.19)

Buechley, L., Peppler, K.A., Eisenberg, M., Kafai, Y.B., 2014. Textile messages : dispatches from the world of e-textiles and education. Peter Lang Publishing Group.

Chamberlain, E., 2012. Tech Manufacturers Got It Wrong: How to Design Electronics For Repair [WWW Document]. ifixit. URL https://www.ifixit.com/News/what-tech-manufacturers-havewrong-how-to-design-electronics-for-repair (accessed 10.31.19).

Charter, M., Keiller, S., 2016. The Second Global Survey of Repair Cafés: A Summary of Findings [WWW Document]. URL https://research.uca.ac.uk/3140/1/The Second Global Survey of Repair Cafes - A Summary of Findings.pdf (accessed 5.13.20).

Chen, A., Tan, J., Tao, X., Henry, P., Bai, Z., 2019. Challenges in Knitted E-textiles, in: Wong, W.K. (Ed.), Artificial Intelligence on Fashion and Textiles. Springer International Publishing, Cham, pp. 129-135.

Cherenack, K., Van Pieterson, L., 2012. Smart textiles: Challenges and opportunities. J. Appllied Phys. 091301. https://doi.org/10.1063/1.4742728

Cole, C., Cooper, T., Gnanapragasam, A., 2016. Extending product lifetimes through WEEE reuse and repair: Opportunities and challenges in the UK. 2016 Electron. Goes Green 2016+, EGG 2016 1-9. https://doi.org/10.1109/EGG.2016.7829857

Cooper, T. (Ed.), 2010. Longer Lasting Products: Alternatives To The Throwaway Society. Gower, Farnham.

Cooper, T., Oxborrow, L., Claxton, S., Goworek, H., Hill, H., McLaren, A., 2016. Strategies to improve design and testing for clothing longevity. London: Defra.

Cooper, T., Oxborrow, L., Claxton, S., Hill, H., Goworek, H., McLaren, A., 2019. Clothing Durability Dozen. Report by Nottingham Trent University for Defra. Nottingham: Nottingham Trent University. 
Defra, 2019. Helping businesses create a greener, more sustainable future through ICT [WWW Document]. URL

https://assets.publishing.service.gov.uk/government/uploads/system/uploads/attachment_data/fil e/840765/defra-industry-guide-ict-sustainability.pdf (accessed 5.13.20).

Defra, 2010. Sustainable Clothing Action Plan [WWW Document]. URL https://www.gov.uk/government/publications/sustainable-clothing-action-plan (accessed 5.13.20).

Department for Business Innovation and Skills, 2016. Textile labelling regulations: guidance on the Textile Products (Labelling and Fibre Composition) Regulations 2012 [WWW Document]. URL https://www.gov.uk/government/publications/textile-products-labelling-and-fibre-compositionregulations-2012-guidance (accessed 5.13.20).

Deploy, 2020. Sustainability [WWW Document]. DEPLOY London. URL https://deployworkshop.com/pages/sustainability (accessed 5.13.20).

Dias, D., Silva Cunha, J.P., 2018. Wearable Health Devices-Vital Sign Monitoring, Systems and Technologies. Sensors (Basel). 18, 2414. https://doi.org/10.3390/s18082414

Dias, T., 2016. Patent WO2016/038342 A1 Electronically Functional Yarns. WO2016/038342 A1; GB2529900B1.

ECMA, 2010. Standard ECMA-341 Environmental Design Considerations for ICT \& CE Products [WWW Document]. URL https://www.ecma-international.org/publications/files/ECMAST/ECMA-341.pdf (accessed 5.13.20).

Eichhoff, J., Hehl, A., Jockenhoevel, S., Gries, T., 2013. Textile fabrication technologies for embedding electronic functions into fibres, yarns and fabrics, Multidisciplinary Know-How for Smart-Textiles Developers. Woodhead Publishing Limited. https://doi.org/10.1533/9780857093530.2.191

Ellen MacArthur Foundation, 2017. A new textiles economy: Redesigning fashion's future [WWW Document]. http://www.ellenmacarthurfoundation.org/publications. URL https://www.ellenmacarthurfoundation.org/assets/downloads/A-New-Textiles-Economy_FullReport_Updated_1-12-17.pdf (accessed 8.11.20).

Environment Agency, 2018. Electrical and electronic equipment (EEE) covered by the WEEE Regulations [WWW Document]. UK Gov. URL https://www.gov.uk/government/publications/electrical-and-electronic-equipment-eee-coveredby-the-weee-regulations/electrical-and-electronic-equipment-eee-covered-by-the-weeeregulations (accessed 8.11.20).

Erdem, D., Yesilpinar, S., Senol, Y., Karadibak, D., Akkan, T., 2016. Design of TENS electrodes using conductive yarn. Int. J. Cloth. Sci. Technol. 28, 311-318. https://doi.org/10.1108/IJCST03-2016-0030

European Parliament Council of the European Union, 2012. DIRECTIVE 2012/19/EU OF THE EUROPEAN PARLIAMENT AND OF THE COUNCIL of 4 July 2012 on waste electrical and electronic equipment (WEEE) [WWW Document]. URL https://eur-lex.europa.eu/legalcontent/EN/TXT/?uri=CELEX:32012L0019 (accessed 10.23.18).

Forti, V., Baldé, C.P., Kuehr, R., Bel, G., 2020. The Global E-waste Monitor 2020: Quantities, flows, and the circular economy potential [WWW Document]. United Nations Univ. (UNU)/United Nations Inst. Train. Res. - co-hosted SCYCLE Program. Int. Telecommun. Union Int. Solid Waste Assoc. URL http://ewastemonitor.info/wpcontent/uploads/2020/07/GEM_2020_def_july1_low.pdf\#. (accessed 8.11.20).

Garmin UK, 2019. Heart rate monitors [WWW Document]. Garmin UK. URL 
https://buy.garmin.com/en-GB/GB/c14662-p1.htm (accessed 2.18.20).

Gonzalez, R., 2017. Science Says Fitness Trackers Don't Work. Wear One Anyway [WWW Document]. Wired. URL https://www.wired.com/story/science-says-fitness-trackers-dont-workwear-one-anyway/ (accessed 5.13.20).

Google, 2020. Google Jacquard [WWW Document]. atap.google.com. URL https://atap.google.com/jacquard (accessed 2.25.20).

Google, 2019. Taking care of your Levi's Commuter Trucker Jacket with Jacquard by Google Jacquard Help [WWW Document]. URL https://support.google.com/jacquard/answer/7536711?hl=en (accessed 6.25.19).

Google, 2017a. Safety \& Regulatory Guide for Levi’s® Commuter ${ }^{\mathrm{TM}}$ Trucker Jacket with Jacquard $^{\mathrm{TM}}$ by Google and the Jacquard snap tag (2017) [WWW Document]. URL https://support.google.com/jacquard/answer/7511968?hl=en (accessed 2.25.20).

Google, 2017b. Jacquard ${ }^{\mathrm{TM}}$ by Google Hardware Limited Warranty (for Levi's ${ }^{\circledR}$ Commuter ${ }^{\mathrm{TM}}$ Trucker Jacket with Jacquard ${ }^{\mathrm{TM}}$ by Google (2017) United States [WWW Document]. URL https://support.google.com/jacquard/answer/7516411 ?hl=en (accessed 2.25.20).

Grishanov, S., 2011. Structure and properties of textile materials, in: Handbook of Textile and Industrial Dyeing: Principles, Processes and Types of Dyes. Elsevier Inc., pp. 28-63. https://doi.org/10.1533/9780857093974.1.28

Gupta, B.S. (Bhupender S.., 2013. Manufacture, types and properties of biotextiles for medical applications, in: Biotextiles as Medical Implants. Woodhead Publishing, pp. 3-47. https://doi.org/https://doi.org/10.1533/9780857095602

Gwilt, A., 2014. What prevents people repairing clothes? : an investigation into community-based approaches to sustainable product service systems for clothing repair. Making Futures Journal. 3. http://shura.shu.ac.uk/8125/1/Gwilt_Alison.pdf (accessed 9.15.20).

HAL 90210, 2017. Jacquard: Google and Levi's "smart jacket" that you can only wash 10 times [WWW Document]. Guard. URL

https://www.theguardian.com/technology/2017/sep/26/jacquard-google-levis-smart-jacketdenim?CMP=share_btn_link (accessed 9.29.17).

Hardy, D.A., Anastasopoulos, I., Nashed, M.-N., Oliveira, C., Hughes-Riley, T., Komolafe, A., Tudor, J., Torah, R., Beeby, S., Dias, T., 2019a. Automated insertion of package dies onto wire and into a textile yarn sheath. Microsyst. Technol. 1-13. https://doi.org/10.1007/s00542-019-04361-y

Hardy, D.A., Rahemtulla, Z., Satharasinghe, A., Shahidi, A., Oliveira, C., Anastasopoulos, I., Nashed, M.N., Kgatuke, M., Komolafe, A., Torah, R., Tudor, J., Hughes-Riley, T., Beeby, S., Dias, T., 2020. Wash Testing of Electronic Yarn. Materials (Basel). 13, 1228. https://doi.org/10.3390/ma13051228

Hardy, D.A., Townsend, K., Kgatuke, M., Salter, E., Downes, T., Harrigan, K., Allcock, S., Dias, T., 2019b. Light My Elbows: A Cycling Jacket Incorporating Electronic Yarn, in: Textile Intersections Conference Proceedings. Loughborough University, London. https://repository.lboro.ac.uk/articles/Light_my_elbows_a_cycling_jacket_incorporating_electro nic_yarn/9741278 (accessed 9.15.20).

Hayward, J., 2019. E-Textiles 2020-2030: Technologies, Markets and Players [WWW Document]. IDTechEx. URL https://www.idtechex.com/en/research-report/e-textiles-and-smart-clothing2020-2030-technologies-markets-and-players/735 (accessed 5.14.20).

Hughes-Riley, T., Dias, T., Cork, C., 2018. A Historical Review of the Development of Electronic Textiles. Fibers 6, 34. https://doi.org/10.3390/fib6020034 
Kadolph, S.J., Marcketti, S.B., 2016. Textiles, 12th ed. Pearson, Boston, MA.

Karana, E., Barati, B., Rognoli, V., Van Der Laan, A.Z., 2015. Material driven design (MDD): A method to design for material experiences. Int. J. Des. 9, 35-54.

Köhler, A., 2013a. Anticipatory Eco-Design Strategies for Smart Textiles. TU Delft University. https://doi.org/10.4233/uuid

Köhler, A., 2013b. Challenges for eco-design of emerging technologies: The case of electronic textiles. Mater. Des. 51, 51-60. https://doi.org/10.1016/j.matdes.2013.04.012

Köhler, A., 2008. End-of-life implications of electronic textiles Assessment of a converging technology. Environ. Manage. iiiee Lund University.

Köhler, A.R., Hilty, L.M., Bakker, C., 2011. Prospective Impacts of Electronic Textiles on Recycling and Disposal. J. Ind. Ecol. 15, 496-511. https://doi.org/10.1111/j.1530-9290.2011.00358.X

Kumar, R., Srivastava, P., Khurana, S., 2016. Synthetic Fibres and Plastics, in: Saraswati Science 8. New Saraswati House (India) Pvt. Ltd., New Dehli.

Langley, E., Durkacz, S., Tanase, S., 2013. Clothing longevity and measuring active use [WWW Document]. Prep. by Ipsos MORI WRAP London. URL https://www.wrap.org.uk/sustainabletextiles/scap/extending-clothing-life/report/measuring-active-life-of-clothing (accessed 5.19.20).

Levi's®, 2019. Where to Recycle Denim \& Jeans [WWW Document]. Off Cuff. URL https://www.levi.com/US/en_US/blog/article/where-to-recycle-your-clothes/ (accessed 5.13.20).

Maitre-Ekern, E., Dalhammar, C., 2016. Regulating Planned Obsolescence: A Review of Legal Approaches to Increase Product Durability and Reparability in Europe. Rev. Eur. Comp. Int. Environ. Law 25, 378-394. https://doi.org/10.1111/reel.12182

Martinho, G., Magalhães, D., Pires, A., 2017. Consumer behavior with respect to the consumption and recycling of smartphones and tablets: An exploratory study in Portugal. J. Clean. Prod. 156, 147-158. https://doi.org/10.1016/j.jclepro.2017.04.039

Mbise, E., Dias, T., Hurley, W., 2015. Design and manufacture of heated textiles. Electron. Text. 117-132. https://doi.org/10.1016/B978-0-08-100201-8.00007-2

Mclaren, A., Goworek, H., Cooper, T., Oxborrow, L., Hill, H., 2016. The Effect of Consumer Attitudes on Design for Product Longevity: The Case of the Fashion Industry, in: Proceedings of Design Research Society 50th Anniversary Conference. pp. 1-16.

McLaren, A., McLauchlan, S., 2015. Crafting sustainable repairs: practice-based approaches to extending the life of clothes [WWW Document]. PLATE Conf. URL https://www.plateconference.org/crafting-sustainable-repairs-practice-based-approachesextending-life-clothes/ (accessed 5.13.20).

O’Connor, S., 2017. Making Wearable Technology Meaningful: Part 1 [WWW Document]. Smart Des. URL https://smartdesignworldwide.com/ideas/making-wearable-technology-meaningful/ (accessed 12.22.17).

Orth, M., 2009. 100 Electronic Art Years [WWW Document]. URL http://www.maggieorth.com/art_100EAYears.html (accessed 5.13.20).

Ossevoort, S.H.W., 2013. Improving the sustainability of smart textiles, Multidisciplinary Know-How for Smart-Textiles Developers. Woodhead Publishing Limited. https://doi.org/10.1533/9780857093530.3.399

Polar UK, 2020. Polar H10 Heart rate monitor chest strap [WWW Document]. URL https://www.polar.com/uk-en/products/accessories/polar_h10_heart_rate_sensor (accessed 2.18.20). 
Poupyrev, I., Gong, N.-W., Fukuhara, S., Karagozler, M.E., Schwesig, C., Robinson, K.E., 2016. Project Jacquard: Interactive Digital Textiles at Scale, in: Proceedings of the 2016 CHI Conference on Human Factors in Computing Systems - CHI '16. Mountain View, CA, USA. https://doi.org/10.1145/2858036.2858176

Rein, M., Favrod, V.D., Hou, C., Khudiyev, T., Stolyarov, A., Cox, J., Chung, C.-C., Chhav, C., Ellis, M., Joannopoulos, J., Fink, Y., 2018. Diode fibres for fabric-based optical communications. Nature 560, 214-218. https://doi.org/10.1038/s41586-018-0390-х

Rosner, D.K., Ames, M.G., 2014. Designing for repair? Infrastructures and materialities of breakdown, in: Proceedings of the ACM Conference on Computer Supported Cooperative Work, CSCW. Association for Computing Machinery, New York, New York, USA, pp. 319-331. https://doi.org/10.1145/2531602.2531692

Sametinger, F., Baker, C., Ranaivoson, H., Bryan-Kinns, N., 2019. WEAR Sustain (Wearable technologists Engage with Artists for Responsible innovation): Sustainability Strategy Toolkit, in: Textile Intersections:12-14th September 2019. Loughborough University, London. https://doi.org/10.17028/RD.LBORO.9724631.V1

Satharasinghe, A., Hughes-Riley, T., Dias, T., 2018. Photodiodes embedded within electronic textiles. Sci. Rep. 8, 16205. https://doi.org/10.1038/s41598-018-34483-8

Scott, R.A., 1988. The technology of electrically heated clothing. Ergonomics 31, 1065-1081. https://doi.org/10.1080/00140138808966745

Sharma, K., 2018. Smart Textile Market by Function (Energy Harvesting, Sensing, Thermoelectricity, Luminescent, and Others) and End User (Healthcare, Military \& Defense, Entertainment, Automotive, Sport \& Fitness) - Global Opportunity Analysis and Industry Forecast, 2014 [WWW Document]. Allied Mark. Res. URL https://www.alliedmarketresearch.com/smarttextile-market (accessed 2.7.18).

Smithers, R., 2019. Christmas jumpers add to plastic pollution crisis, says charity [WWW Document]. Guard. URL https://www.theguardian.com/environment/2019/dec/06/christmas-jumpers-add-toplastic-pollution-crisis-says-charity (accessed 2.25.20).

The European Parliament and the Council of the European Union, 2011. DIRECTIVE 2011/65/EU OF THE EUROPEAN PARLIAMENT AND OF THE COUNCILof 8 June 2011 on the restriction of the use of certain hazardous substances in electrical and electronic equipment [WWW Document]. Off. J. Eur. Union. URL https://eurlex.europa.eu/LexUriServ/LexUriServ.do?uri=OJ:L:2011:174:0088:0110:en:PDF (accessed 8.18.20).

Townsend, Katherine, Kettley, S., Walker, S., 2020. The Electric Corset and Other Future Histories, in: Townsend, K., Solomon, R., Briggs-Goode, A. (Eds.), Crafting Anatomies: Archives, Dialogues, Fabrications. Bloomsbury Publishing Plc, London, England, pp. 87-107.

United Kingdom, 2012. CE marking [WWW Document]. Dep. Business, Energy Ind. Strateg. URL https://www.gov.uk/guidance/ce-marking (accessed 2.25.20).

Veja, P., 2014. An investigation of integrated woven electronic textiles (e-textiles) via design led processes. Brunel University London.

Wickenden, R., Mclaren, A., Hardy, D.A., 2019. Electronic Textiles and Product Lifetimes: Teardowns, in: 3rd PLATE Conference. Berlin.

Wieser, H., Tröger, N., 2016. Exploring the inner loops of the circular economy: Replacement, repair, and reuse of mobile phones in Austria. J. Clean. Prod.

https://doi.org/10.1016/j.jclepro.2017.11.106

WRAP, 2018. Resource Revolution: Creating the Future [WWW Document]. WRAP. URL 
http://www.wrap.org.uk/about-us/our-plan (accessed 5.13.20).

WRAP, 2017a. Switched on to value : Powering business change [WWW Document]. URL http://www.wrap.org.uk/sustainable-electricals/switched-on-to-

value?utm_source=media\&utm_medium=wrap\&utm_campaign=switched_on_to_value_2017\& utm_content=b_r_m (accessed 5.14.20).

WRAP, 2017b. Valuing our clothes: the cost of UK fashion [WWW Document]. URL http://www.wrap.org.uk/sites/files/wrap/valuing-our-clothes-the-cost-of-uk-fashion_WRAP.pdf (accessed 5.14.20).

WRAP, 2013. Guidance on design for longevity - denim [WWW Document]. URL https://www.wrap.org.uk/sites/files/wrap/Design for longevity - denim_0.pdf (accessed 5.13.20).

Yang, K., Meadmore, K., Freeman, C., Grabham, N., Hughes, A.-M., Wei, Y., Torah, R., GlancGostkiewicz, M., Beeby, S., Tudor, J., Yang, K., Meadmore, K., Freeman, C., Grabham, N., Hughes, A.-M., Wei, Y., Torah, R., Glanc-Gostkiewicz, M., Beeby, S., Tudor, J., 2018. Development of User-Friendly Wearable Electronic Textiles for Healthcare Applications. Sensors 18, 2410. https://doi.org/10.3390/s18082410

Zallio, M., Berry, D., 2017. Design and Planned Obsolescence. Theories and Approaches for Designing Enabling Technologies. Des. J. 20, S3749-S3761. https://doi.org/10.1080/14606925.2017.1352879

Zeng, W., Shu, L., Li, Q., Chen, S., Wang, F., Tao, X.-M., 2014. Fiber-Based Wearable Electronics: A Review of Materials, Fabrication, Devices, and Applications. Adv. Mater. 26, 5310-5336. https://doi.org/10.1002/adma.201400633

Zysset, C., Kinkeldei, T., Münzenrieder, N., Petti, L., Salvatore, G., Tröster, G., 2013. Combining electronics on flexible plastic strips with textiles. Text. Res. J. 83, 1130-1142. https://doi.org/10.1177/0040517512468813 